\title{
Impact of Running Exercise Duration on Leg Muscle Strength among the people Joining Indorunners Bandung Community
}

\author{
Agaprita Eunike Sirait, ${ }^{1}$ Yuni Susanti Pratiwi, ${ }^{2}$ Ginna Megawati $^{3}$ \\ ${ }^{1}$ Faculty of Medicine Universitas Padjadjaran, ${ }^{2}$ Department of Anatomy, Cell Biology and \\ Physiology Faculty of Medicine Universitas Padjadjaran, ${ }^{3}$ Department of Public Health Faculty of \\ Medicine Universitas Padjadjaran
}

\begin{abstract}
Background: Indorunners Bandung is a community for runners that has a routine exercise schedule for running around the city of Bandung. Exercise, like running, if is conducted in an accurate duration may improve physical fitness. One of the aspects of physical fitness is leg muscles strength. Many people fail to fathom the importance of exercise duration, so, they fail to get the benefit. The aim of this study was to discover the impact of running exercise duration on leg muscles strength among the people joining Indorunners Bandung community.

Methods: A comparative study was conducted to 41 people, 31 males and 10 females, of Indorunners Bandung community from September to November 2015. Each participant filled a questionnaire about his/her personal data, and then was grouped by his/her duration of exercise per week, which were 150 minutes/week, 150-299 minutes/week, and 300 minutes/week or more. The respondents were measured for their leg muscles strength. The data collected were analyzed using ANOVA test.

Results: There was significant difference of lower extremities muscle strength both in men $(p<0.001)$ and women $(p=0.029)$. These results showed that there was a difference in leg muscles strength among the people joining Indorunners Bandung community with different exercise duration per week.

Conclusions: There is a difference in leg muscles strength among the people joining Indorunners Bandung community with different exercise duration per week. [AMJ.2017;4(1):69-72]
\end{abstract}

Keywords: Exercise, Indorunners, leg muscles strength, running

\section{Introduction}

Exercise has several good benefits, for example, maintaining physical fitness. ${ }^{1}$ One of the most common physical activities is running. Based on a statistical survey, the number of runners was increasing from less than five million people in 1990 to 13.8 million in $2011 .^{2}$ To support the need to assemble and exercise together, runners make a specific community. The community, like Indorunners Bandung, usually consists of committed runners that have a routine schedule for exercising.

Muscles strength enhancement is one of the benefits of exercise. Muscles significantly used in runners are leg muscles. Many runners do not fathom the importance of duration of exercise per week to get the physical fitness benefit, like enhancing leg muscles strength. The previous study stated to enhance leg muscles strength, exercise must be executed at least 150 minutes in one week, and at least 300 minutes per week for more benefit. ${ }^{3}$ There has not been any study about the impact of duration of exercise per week on leg muscles strength in runners community; therefore, this study was conducted to discover that topic, and the runners community taken as samples are the people joining Indorunners Bandung.

\section{Methods}

A cross-sectional study was approved by the Health Research Ethics Committee of Faculty of Medicine Universitas Padjadjaran (Number: 434/UN6.C1.3.2/KEPK/PN/2015) and the chief of Indorunners Bandung community. The study was conducted from September to November 2015 in MG\&Co Café Bandung which was the meeting point of Indorunners Bandung

Correspondence: Agaprita Eunike Sirait, Faculty of Medicine, Universitas Padjadjaran, Jalan Raya Bandung-Sumedang Km.21, Jatinangor, Sumedang, Indonesia, Phone: +628125563001 Email:agaprita@yahoo.com 
Table 1 Distribution of Participants' Characteristics

\begin{tabular}{llcccc}
\hline & Group 1* & Group 2** & Group 3*** & Total \\
\hline Sex & & & & \\
& Male & $9(21.9 \%)$ & $12(29.2 \%)$ & $10(24.3 \%)$ & $31(75.6 \%)$ \\
& Female & $4(9.7 \%)$ & $5(12.1 \%)$ & $1(2.4 \%)$ & $10(24.3 \%)$ \\
& Total & $13(31.7 \%)$ & $17(41.4 \%)$ & $11(26.8 \%)$ & $41(100 \%)$ \\
Sports & & & & \\
& No other exercises & $7(17 \%)$ & $6(14.6 \%)$ & $4(9.7 \%)$ & $17(41.4 \%)$ \\
& Doing other exercises & $6(14.6 \%)$ & $11(26.8 \%)$ & $7(17 \%)$ & $24(58.5 \%)$ \\
& Total & $13(31.7 \%)$ & $17(41.4 \%)$ & $11(26.8 \%)$ & $41(100 \%)$ \\
\hline
\end{tabular}

Note: *: Exercise duration less than 150 minutes/week, ${ }^{* *}$ : Exercise duration 150-299 minutes/week, ***: Exercise duration more than equals to 300 minutes/week

community, West Java, Indonesia. The subjects were all people joining Indorunners Bandung community. The population of Indorunners Bandung is not fixed because there was no membership data. Therefore, the sampling method was consecutive sampling. The inclusion criteria was 18-64 years of age, not using drugs for muscle strength enhancement recently, not in a fatigue condition, not having chronic diseases, routinely running for three months, and no history of musculoskeletal trauma in the past six months. Participants that could not complete the measurement procedure were excluded from the study. A total of 41 participants, 10 females and 31 males, were collected.

The participants were given information about this study, and the participants agreeing to follow the study were given informed consent letter. A preliminary screening test using a questionnaire about their personal data, running history, and health history related to the inclusion criteria was conducted.
Moreover, the participants were measured for their leg muscles strength (kg) with a leg dynamometer three times with a standard procedure, knee bended to 130-140 degrees to ensure that only leg muscles were used. The highest value of the results was used for the muscle strength data.

Based on the data from the questionnaire, the subjects then were categorized into three groups based on their exercise per week's duration. Those were, group 1: less than 150 minutes/week consisting of 13, group 2: 150-299 minutes/week consisting of 17 participants, and group 3: more than or equal to 300 minutes/week consisting of 11 participants. All the data were analyzed by computer. The normality of data was tested by using Saphiro-Wilk, and the data were analyzed by Analysis of Variance (ANOVA). The confidence interval used was $95 \%$, and considered significant if the $\mathrm{p} \leq 0.05$. The data for male and female were analyzed individually

Table 2 Distribution of Leg Muscles Strength and Exercise Duration per Week

\begin{tabular}{llccc}
\hline & & n & Mean (SD) (kg) & p value \\
\hline Male & Group 1* & & & \\
& Group 2** & 9 & $88.33(4.87)$ & $127.50(35.34)$ \\
& Group 3*** & 12 & $190.65(36.63)$ & \\
Female**** & & 10 & & \\
& Group 1* & & $48.25(2.32)$ & 0.029 \\
& Group 2** & 4 & $57.14(12.94)$ & \\
\hline
\end{tabular}

Note: *: Group 1 for exercise duration less than 150 minutes/week, **: Group 2 for exercise duration 150-299 minutes/ week, ***: Group 3 for exercise duration more than equals 300 minutes/week, ****: Leg muscles strength was constant in Group $3(\mathrm{n}=1)$, it has been omitted. The muscle strength of one person in group 3 was $87 \mathrm{~kg}$. 


\section{Results}

Male was the predominant sex in this study. Moreover, most of the participants were doing other sports other than running. The varieties of sports exercised by the participants were weight lifting, tennis, swimming, futsal, cycling, aerobic dance, and martial arts.

Group 3, which consisted of people exercising for more than equals 300 minutes per week, had the highest mean of muscle strength in both sex. Moreover, the male group had higher mean than the female group..

\section{Discussions}

One of the benefits of exercise like running is improving physical fitness. Muscle strength is one of the physical fitness aspects. Muscles significantly used in runners are leg muscles. ${ }^{4}$ Leg is a part of lower extremities, which are extensions from the trunk that have several functions including to support body weight, to move from one place to another, and to maintain balance. $^{5}$ In runners, leg muscle strength is also important for maintaining the running velocity and acceleration. ${ }^{6}$ Muscle strength, specifically leg muscles strength was the variable measured in this study. If conducted in a correct duration, the leg muscles strength enhancement can be achieved. ${ }^{7}$

The result of this study was corresponding to the previous study which said there is a correlation of exercise duration per week to muscle strength. ${ }^{8}$ There was a difference between male and female's muscle strength; in female the mean was lower than in male. This result was supported by the previous study that said sex is one of contributing factor in muscle strength. Male usually has higher muscle strength due to the physical activity and physiologic factor. ${ }^{9}$ Other than sex, variation in muscle strength may be caused by Body Mass Index (BMI). Higher BMI or obesity is associated in low muscle quality therefore causing a lower muscle strength. ${ }^{10}$

Running is an aerobic activity. This activity is highly correlated to cardiovascular fitness. Cardiovascular fitness is important for blood circulation control, to avoid heart diseases, and also for weight loss. In enhancing muscle strength, aerobic exercise has less impact than muscle strength training like weight lifting. Therefore, to increase muscle strength, it is suggested to do muscle strength training two times in a week. ${ }^{11}$

Public health experts and World Health Organization recommend people to do a moderate intensity exercise (cycling, running, swimming) at least 30 minutes a day or 150 minutes a week. To get additional benefit, like weight loss, the duration need to be increased to 60 minutes a day or 300 minutes a week. ${ }^{3}$

Limitation of this study was due to a limited time, there were only a few female respondents of this study. From this study it can be concluded that there is a difference in leg muscles strength among the people joining Indorunners Bandung community with different exercise duration per week. This study showed that runners exercising at least 300 minutes per week have higher muscle strength. Therefore, it is recommended for all runners to consider the duration of the exercise per week to get the benefit of running, like enhancing muscles strength. Running with fellow runners in a community may help runners to commit to a routine schedule of running, so the target duration of exercise per week may be accomplished. For further research, the correlation of exercise duration to leg muscles strength may be explored.

\section{References}

1. Bredeweg SW, Kluitenberg B, Bessem B, Buist I. Differences in kinetic variables between injured and noninjured novice runners: A prospective cohort study. J Sci Med Sport. 2013;16(3):205-10.

2. Reinking MF, Austin TM, Hayes AM. A Survey of exercise and related leg pain in community runners. Int J Sport Phys Ther. 2013;8(3):269-76.

3. WHO. Global recommendations on physical activity for health. Geneva: WHO Library Cataloguing Data; 2010.

4. Rauner A, Mess F, Woll A. The relationship between physical activity, physical fitness and overweight in adolescents: a systematic review of studies published in or after 2000. BMC Pediatrics. 2013;13(1):19-19.

5. Moore KL, Arthur FD, Anne MR. Moore clinically oriented anatomy. 6th ed. Philadelphia: Lippincott Williams \& Wilkins; 2014.

6. Chelly MS, Chérif N, Amar MB, Hermassi S, Fathloun M, Bouhlel E, et al. Relationships of peak leg power, 1 maximal repetition half back squat, and leg muscle volume to 5-m sprint performance of junior soccer players. Journal of Strength and Conditioning Research. 2010;24(1):26671.

7. Gimenez P, Arnal PJ, Samozino P, Millet GY, Morin J. Simulation of uphill/downhill 
running on a level treadmill using additional horizontal force. J Biomech. 2014;47(10):2517-21.

8. Willis FB, Smith FM, Willis AP. Frequency of exercise for body fat loss: a controlled cohort study. Journal of Strength and Conditioning Research. 2009;23(8):237780.

9. Harbo T, Brincks J, Andersen H. Maximal isokinetic and isometric muscle strength of major muscle groups related to age, body mass, height, and sex in 178 healthy subjects. Eur J Appl Physiol.
2012;112(1):267-75.

10. Cooper R, Hardy R, Bann D, Aihie Sayer A, Ward K, Kuh D, et al. Body mass index from age 15 years onwards and muscle mass, strength, and quality in early old age: findings from the MRC National Survey of Health and Development. J Gerontol A Biol Sci Med Sci. 2014;69(10):1253-59.

11. Knuttgen HG. Strength training and aerobic exercise: comparison and contrast. Journal of Strength and Conditioning Research. 2007;21(3):973-8. 